\title{
Acadêmicos de Medicina e Suas Concepções sobre "Ser Médico"
}

\author{
Medical Students and Their Ideas About \\ "Becoming a Doctor"
}

\author{
Rosangela Ziggiotti de Oliveira ${ }^{I}$ \\ Maria Bernadete Gonçalves \\ Luiza Marta Bellini
}

\section{PALAVRAS CHAVE: \\ - Educação Médica \\ - Estudantes de Medicina \\ - Percepção.}

\section{KEYWORDS:}

- Medical Education

- Medical Students

- Perception.
Recebido em: 28/04/2010

Reencaminhado em: 09/09/2010

Aprovado em: 09/02/2011

\section{RESUMO}

O objetivo deste trabalho foi identificar expectativas, preconceitos e sentimentos experimentados por acadêmicos de Medicina em relação à sua vivência no curso da Universidade Estadual de Maringá (PR). Foi analisado o depoimento escrito de 73 alunos da disciplina Saúde Pública, da quarta série, que responderam duas questões abertas no primeiro dia de aula. Pretendia-se conhecer o pensamento desses alunos sobre a formação e a profissão médica antes de entrarem no curso e na quarta série. Da leitura inicial, emergiram cinco categorias: a amizade e o coleguismo como fundamentos no curso; docência médica; a escola e o desenrolar do curso; o médico e a profissão; impressões sobre si mesmo. O resultado indica que a idealização do ingresso foi derrotada; no quarto ano, os alunos entendem melhor o curso; continuam comprometidos e preocupados com a formação e levam para o internato a expectativa de um aprendizado conciliador. Embora mais maduros e satisfeitos com a escolha, foram identificados acadêmicos que não encontraram estratégias para lidar com as adversidades do curso.

\begin{abstract}
The aim of this study was to identify expectations, prejudices, and feelings among medical students in relation to their experience in medical school at the State University in Maringá, Paraná, Brazil. The study analyzed written interviews of 73 students who were currently taking the course in public health during the fourth year of undergraduate training, and who answered two open questions on the first day of classes. The idea was to examine the students' thoughts about medical training and the medical profession before they started the fourth year. Five categories emerged from the initial reading of the answers: friendship and camaraderie as foundations during the course; medical teaching; the medical school and development of the course; physicians and the profession; and self-impressions. The results indicate that idealization of successful entry into medical school had already waned; by the fourth year, students had a better grasp of the course; they were still committed to and concerned with their training; and they were ready to enter internship with expectations of a conciliatory learning process. Although they were more mature and satisfied with their choice, the study identified students who had still failed to find strategies to deal with the adversities of medical school.
\end{abstract}




\section{INTRODUÇÃO}

Uma das primeiras investigações sobre a cultura médica na formação do profissional de medicina é intitulada Rapazes de branco, feita em 1961, por Becker e outros estudiosos ${ }^{1}$. Foi realizado um estudo sociológico em 1956-57 na escola médica da Universidade de Kansas, em que os pesquisadores atuaram como "observadores participantes", com o objetivo "de descobrir o que uma faculdade de Medicina faz por seus estudantes, além de proporcionar uma educação técnica". A hipótese era que os estudantes se formavam médicos com ideias sobre a medicina e sua prática diferentes das que tinham ao ingressar na escola. Desse modo, durante dois meses, os pesquisadores se inseriram nas atividades do curso, em palestras, em exercícios práticos, em alojamentos estudantis e em todos os departamentos do hospital ${ }^{1}$. Eles chegaram a diversas conclusões, dentre as quais: os estudantes têm dificuldade de utilizar adequadamente seu tempo; a escola não aponta o que é necessário saber ao término do curso; a escola endurece o aluno; a ideologia da instituição se contrapõe à orientação prática dos alunos. O estudo identificou ainda o surgimento de certo cinismo, embora o idealismo persistisse na maioria dos alunos até a formatura. Segundo esse estudo, ao término do curso, os alunos superam todos os embates, embora não fique claro que forças contribuem para isso ${ }^{1}$.

O tema dessa pesquisa, certamente, ainda interessa aos educadores que estudam a identidade profissional daqueles que passam por um curso de Medicina, que sabemos ser árduo e complexo. De certa maneira, a formação passa pela identidade profissional, educação técnica e compreensão do que é ser médico em termos coletivos e individuais.

O objetivo deste trabalho foi identificar expectativas, preconceitos e sentimentos vivenciados pelos acadêmicos de Medicina da Universidade Estadual de Maringá (PR) com relação à sua formação profissional, ao curso, ao corpo docente, aos colegas e às impressões sobre si mesmos. O curso de Medicina foi implantado em 1988 e, atualmente, oferece 40 vagas anuais. Embora a estrutura curricular tenha sofrido algumas modificações ao longo dos anos, o modelo pedagógico tem características tradicionais. $\mathrm{O}$ regime curricular é seriado anual, e o ensino se estrutura em três ciclos: o básico, que compreende as disciplinas da primeira e segunda séries; o intermediário, da terceira e quarta; e o profissionalizante, que compreende a quinta e sexta séries do curso, o internato.

\section{MATERIAL E MÉTODOS}

Trata-se de uma pesquisa qualitativa. $\mathrm{O}$ objeto de estudo foi o depoimento escrito de alunos que ingressaram na disciplina Estágio em Saúde Pública, ofertada na quarta série do curso de Medicina da Universidade Estadual de Maringá em 2006, 2007 e 2008. O instrumento utilizado na coleta dos dados foi constituído por duas perguntas abertas, aplicado a alunos voluntários no primeiro dia de aula, nos três anos citados. A primeira pergunta indagava o que os alunos pensavam sobre a formação e a profissão médica antes de entrar no curso de Medicina; e a segunda, o que pensavam então, na quarta série. Embora todos os alunos presentes no primeiro encontro tenham respondido o questionário, muitos destes foram extraviados. Assim, não houve preocupação em estabelecer um rigor metodológico do instrumento, já que inicialmente ele não fez parte de um projeto de pesquisa. $\mathrm{O}$ interesse inicial dos docentes pelas respostas foi identificar os sentimentos dos acadêmicos quanto à formação médica e reconhecer as expectativas em relação à disciplina. Entretanto, devido à riqueza do conteúdo dos textos produzidos, optou-se por realizar o estudo, fazer uma análise e divulgar os resultados.

Para extrair os significados de cada depoimento escrito dos alunos, foram utilizadas técnicas de análise de conteúdo preconizadas por Bardin², envolvendo as seguintes etapas: (a) pré-análise, para identificar os dados no contexto dos relatos; (b) exploração e categorização das declarações; (c) interpretação dos dados, subsidiada pelas referências teóricas e explicativas levantadas no estudo. As categorias foram definidas a partir da pré-análise dos dados, que foram explorados seguindo as regras de: exaustividade, que diz respeito à abrangência de todos os aspectos escritos pelos acadêmicos relacionados aos dois momentos do curso; representatividade, que indica dar voz a todo o universo pretendido; homogeneidade, dimensão que buscou obedecer a critérios precisos de escolha dos temas; pertinência, pela qual o material estudado deve ser coerente com os objetivos do trabalho.

O estudo foi aprovado pelo Comitê de Ética e Pesquisa em Seres Humanos, da Universidade Estadual de Maringá, em 13/10/2008.

\section{RESULTADOS E DISCUSSÃO}

Sabemos que a preferência por certa profissão está vinculada à identidade profissional, que pode ocorrer de modo precoce ou mais tardiamente na vida. Em geral, esta identidade começa a se formar no final da adolescência, quando, frequentemente, todos os elementos que ingressam no mundo psíquico do indivíduo fazem parte da sua escolha: as habilidades que desenvolveu até o momento, as imagens registradas em seu mundo interior relacionadas às profissões, suas expectativas em relação a si próprio, suas condições materiais, seus gostos, a profissão das pessoas que lhe são significativas, seus limites e possibilidades, tudo aquilo que deseja afirmar e negar ${ }^{3,4}$. 
Quanto à profissão médica, alguns autores identificam como fatores decisivos na escolha do curso a possibilidade de salvar vidas, o círculo de amizades, as relações familiares, a possibilidade de melhorar a qualidade de vida de outras pessoas e a inclinação para ciências biológicas ${ }^{5}$. Num primeiro momento, o aluno tende a caracterizar a escola como uma instância que vai transformá-lo no profissional que ele idealiza. Quando as comemorações de ingresso vão se distanciando, começam a aparecer os desapontamentos relacionados às questões didáticas, de conteúdo, do professor e da estrutura da escola.

Neste trabalho, estudou-se o depoimento escrito de 73 estudantes e, mediante a exploração destas informações, emergiram cinco categorias de análise: a amizade e o coleguismo como fundamentos no curso; a docência médica; a escola e o desenvolvimento do curso; o médico e sua prática; e as impressões sobre si mesmo.

\section{A amizade e o Coleguismo como Fundamentos do Curso}

Antes de sua entrada no curso, os acadêmicos já valorizavam os relacionamentos interpessoais, aqui expressos em relação ao colega/amigo, trazendo na bagagem o companheirismo, a inteligência e o orgulho:

"[...] Parceria e coleguismo, o curso e a faculdade seriam uma nova família."

"[...] Na minha turma haveria um desejo de bem-estar comum, em que o coletivo estaria acima do eu."

"[...] Colegas mais amistosos, competição saudável sem deslealdade."

Os colegas são idealizados como pessoas diferentes e dotados de capacidades especiais:

"[...] Os colegas seriam pessoas sonhadoras como eu, querendo ajudar os outros."

"[...] Os colegas seriam pessoas extremamente dedicadas, estudiosas, esforçadas."

"[...] Quem vê de fora os estudantes de Medicina acaba rotulando como semideuses, pessoas inteligentíssimas, esforçadas, capazes, determinadas e praticamente sem defeitos."

No quarto ano, os acadêmicos percebem que o ambiente competitivo iniciado no vestibular permanece na sala de aula. Nesse período, os grupos tendem a se desfazer, formam-se subgrupos, disputando aquilo que poderá trazer prestígio e futuras vantagens: iniciação científica, ligas, monitorias, participação em congressos e outras atividades extracurriculares.

"[...] Maior frustração é a competição entre os alunos, que aumenta a cada dia."
"[...] O individual impera sobre o coletivo, a caminhada é solitária."

"[...] Alguns são prepotentes, desprezam os colegas do curso e de outros."

Os estudantes se ressentem da pouca vida acadêmica, não apenas pelas exigências do curso, mas também, provavelmente, pela ausência de um centro de convivência na escola, um espaço comum que favoreça a integração. Isto pode ser explicado pelo fato de o ciclo intermediário do curso ser desenvolvido quase exclusivamente num bloco didático junto ao hospital universitário, distanciando os acadêmicos do campus onde estão os outros cursos de graduação.

"[...] Sinto-me feliz, realizado, embora tenha aproveitado pouco a vida acadêmica."

"[...] temos pouca vida acadêmica."

Apesar dessas considerações, a amizade continua um laço afetivo valorizado, destacado por eles como atenuante:

"[...] Apesar de ter me desapontado com o "paraíso" que pensei que fosse a faculdade, isso foi superado pelos amigos que fiz na sala e no curso."

"[...] Fiz boas amizades, bons companheiros."

"[...] Não imaginava que faria amizades tão sólidas e importantes como fiz. Passamos muito mais tempo com nossos amigos e colegas do que com nossa própria família."

Nesses depoimentos, é possível identificar como o papel dos amigos nesta fase da vida se fortalece, a ponto de superar os laços afetivos familiares, como defendem alguns autores ${ }^{6}$, possivelmente pela intensa convivência a que são submetidos. Para outros, a busca por relacionamentos é motivada por necessidades e preocupações vigentes em cada estágio da vida ${ }^{7}$. Além disso, a entrada na universidade requer do indivíduo ajustamento emocional para construir um novo sistema de apoio social, uma renegociação dos relacionamentos familiares e amizades preexistentes.

\section{A Docência Médica}

Antes do ingresso no curso de Medicina, o docente é idealizado como professor com didática impecável. Gosta de ensinar, é próximo do aluno, ético, autêntico, sabe tudo e estimula o aprendizado:

"[...] Os professores seriam rigorosos, mas justos e aptos a acolher o aluno na busca do aprendizado, agindo com imparcialidade e justiça." 
"[...] Que os professores, além de mestres, seriam amigos."

"[...] Que eles seriam mais interessados."

A expectativa dos acadêmicos vem ao encontro de relatos da literatura que atribuem aos docentes duas funções essenciais: incentivadora, que aproveita a curiosidade e o interesse do aluno, e orientadora, que ajuda a construir seu conhecimento. (Haidt, 1994: 57, cit. em 8 e 9). Entretanto, no quarto ano, os acadêmicos visualizam as dificuldades da docência, apontadas por alguns autores que abordam o insuficiente domínio didático-pedagógico nos professores do ensino superior ${ }^{8-11}$ :

"[...] Eu queria mais professores e menos médicos."

"[...] O médico, em geral, não sabe ser docente."

"[...] Esperava mais dos docentes: competência e compromisso."

Em geral, nas escolas médicas não existe preparo pedagógico específico que qualifique o profissional médico para a docência. Este acredita que, por ser especialista no assunto, estaria apto a ensinar. Com frequência, o professor é contratado pela competência técnica e, às vezes, pelo desempenho como pesquisador, como se a didática estivesse implicitamente assegurada ${ }^{8}$. A prática pedagógica é considerada o domínio específico da profissão docente, o que define a identidade profissional do professor, pois reflete as concepções deste sobre as funções profissionais e como devem ser desempenhadas. Os alunos também apontam a competição entre os docentes e comentam sobre eles:

\section{"[...] também competem." \\ "[...] Há grande competitividade entre as pessoas; entre alu- nos e entre os professores." \\ "[...] Há bons, ótimos e péssimos professores; os ruins sabem o conteúdo, mas não querem explicar."}

Quanto à integração docente, a percepção do pouco diálogo entre eles pode ser favorecida pelo fato de o curso se desenvolver até o quarto ano com base em disciplinas:

\section{"[...] os professores não conversam muito entre si..." \\ "[...] E nas disciplinas com muitos docentes também falta co- municação entre eles."}

Alguns autores acreditam que o sistema de disciplinas, na organização curricular, contribui para o trabalho individual do docente, pois cada uma delas é independente e não tem comunicação com as demais, o que implica fragmentação do ensino e falta de integração do conteúdo ${ }^{12}$. Mesmo nas disciplinas com diversos docentes, os acadêmicos percebem que o diálogo não é uma constante.
Quanto ao processo de ensino-aprendizagem, os acadêmicos fizeram comentários opostos. Enquanto alguns descobrem o prazer do autoaprendizado, outros esperam do professor toda a iniciativa, sugerindo que ainda não parece natural se lançarem na busca do conhecimento:

\section{"[...] hoje acredito mais é no autoaprendizado." \\ "[...] Ajudam, auxiliam, se o aluno for atrás, buscar."}

Alguns educadores enfatizam que, embora determine os conteúdos e tenha a iniciativa no ensino, o professor não pode prescindir da interação com o aluno; a reciprocidade é essencial no aprendizado ${ }^{9}$. No entanto, para que isto ocorra, é necessário que ambos, docentes e alunos, desenvolvam habilidades de investigação, descoberta e investimento nos estudos. A adequada capacitação dos professores pode ser determinante nesse processo.

\section{A Escola e o Desenrolar do Curso}

Vencido o desafio e as dificuldades do vestibular, percebe-se que os estudantes de Medicina chegam à faculdade repletos de sonhos, fantasias e ideais. Para eles, ser médico era um aspecto referente apenas ao tempo, como se estar iniciando esta formação fosse suficiente para transformá-los nesse profissional. Embora reconheçam a necessidade de compromisso e responsabilidade com o curso, esperam um cotidiano menos desgastante que o período pré-vestibular:

\footnotetext{
"[...] O mais dificil era passar no vestibular, teria problemas menores ou nenhum."

"[...] Nada seria pior que passar por esse vestibular: tensão, nervosismo, ansiedade; a responsabilidade era de passar; o curso seria bem mais fácil."

"[...] Paixão era suficiente, a partir do momento em que eu entrasse, a pressão e o estresse diminuiriam, já que estaria fazendo o curso que sempre quis."
}

Após o ingresso no curso, os jovens querem descansar e aproveitar para fazer aquilo de que tiveram de se privar ao estudarem dias, meses e até mesmo anos. Ainda não têm consciência do empenho, dedicação e até pressões a que muitas vezes serão submetidos durante a graduação.

"[...] O curso era muito mais festa, que tivesse que estudar menos. E que então eu teria um tempo para descansar da época estressante do cursinho."

"[...] O curso seria mais leve, teria tempo para relaxar do cursinho; não tinha noção de tanta cobrança; sobraria tempo para viver, fazer outras coisas." 
Isto está de acordo com o observado por alguns autores que relatam a entrada na faculdade, para o acadêmico de Medicina, como o continente idealizado, onde não haverá mais angústia, insegurança ou exigências; pelo contrário, as expectativas serão satisfeitas e será possível finalmente realizar o desejo de ser médico, muitas vezes presente desde a infância ${ }^{3}$ :

"[...] Sonhava muito; roupa branca, plantões, cirurgia, professores."

"[...] O curso era difícil, mas ao final dele eu seria capaz de resolver qualquer problema de saúde."

No depoimento dos alunos, percebe-se o quanto desconheciam o processo de ensino-aprendizagem a ser vivenciado na graduação:

"[...] Eu conseguiria aprender nas aulas e com os livros."

"[...] Achava que me sentiria mais realizada, pois era tudo o queria fazer; teria mais interesse em estudar."

No quarto ano, os acadêmicos relatam desapontamentos. Frequentemente, nos primeiros anos, constatam que não conseguem acompanhar a contento a quantidade de matérias, até obtêm notas mais baixas. Isto contrasta com a autoimagem de bom aluno antes da entrada na faculdade. Percebem que o curso é mais teórico, há pouco contato com o paciente, a carga horária é densa, as aulas são ricas em conteúdo e, muitas vezes, vazias de significado.

"[...] O curso é difícil, dedicação integral, como a profissão, não tinha ideia de quão difícil seria o curso."

"[...] A única coisa que me desagrada bastante no curso é a quantidade absurda de provas e conteúdos muito aprofundados em determinadas disciplinas para a formação de um médico generalista."

"[...] Se estuda sob pressão (provas e provas) não pelo prazer de aprender; esqueço tudo; a cada dia fica mais difícil, nunca estudo tudo para as provas."

Para alguns pesquisadores, a aprendizagem só se estabelece se os estudantes conseguem atribuir significado aos conteúdos, relacionando sua aplicabilidade às situações a que dizem respeito $^{8,9}$. No curso de Medicina, é o contato com os pacientes e a comunidade que pode dar sentido aos conteúdos teóricos.

A disposição curricular em três ciclos, com práticas muito tímidas nos primeiros anos e concentradas essencialmente no período do internato, adia a percepção de uma aprendizagem mais significativa na formação. Isto é evidenciado no depoimento dos estudantes:
"[...] A prática até agora parece muito distante, ficamos restritos aos livros."

"[...] Eu associaria a teoria à prática, e o curso ficaria dinâmico."

"[...] Há uma dicotomia entre a teoria e a prática."

"[...] Esperava ter contato com o paciente já no inicio do curso e saberia primeiros socorros no primeiro ano."

Além disso, é possível que as dificuldades identificadas pelos acadêmicos com relação ao curso se acentuem no quarto ano. Alguns estudos indicam que o terceiro e o quarto anos das escolas médicas levam a uma sobrecarga ${ }^{14,15}$ enfatizada nos depoimentos dos alunos:

\section{[...] Há excesso de carga horária." \\ "[...] O quarto ano é muito desgastante." \\ "[...] É preciso estudar mais do que eu esperava; por mais que estude, sempre sobra muito para aprender; o curso é difícil." \\ "[...] Há um excesso de matérias ditas básicas sobrecarregan- do as matérias médicas no terceiro e quarto anos."}

Para alguns autores, o estresse referido neste período pode ser atribuído ao confinamento das matérias e ao acúmulo de provas nos últimos anos do ciclo intermediário. Isto, em grande parte, é agravado pela expansão de dois anos do internato, sem redução da carga horária das disciplinas já existentes ${ }^{11,16}$. Mesmo com as lacunas identificadas no ensino, alguns substituem as dificuldades enfrentadas pelo prazer do estudo da clínica das disciplinas do ciclo profissionalizante:

"[...] Sou mais entusiasmado, me apaixonei pelo curso, disciplinas, amo o que faço."

"[...] Muito prazeroso lidar com pacientes; sinto satisfação com as matérias clínicas."

Também é possível observar que as expectativas dos acadêmicos se direcionam para os próximos dois anos do internato, momento em que apostam harmonizar os conhecimentos e consolidar o aprendizado:

"[...] Não estou preparada para entrar no internato; não sei quase nada; só de pensar que terei um paciente em minhas mãos." "[...] O internato é o momento de maior aprendizado."

"[...] No internato terei que estudar bastante e me preparar para uma boa residência."

"[...] Espero que os dois próximos anos sejam melhores."

Realmente, o internato se caracteriza como um aprender fazendo ${ }^{13,18}$. Nele, há possibilidade de ampliar, integrar conhecimentos, adestrar técnicas, habilidades e outros atributos essenciais a essa última etapa da formação médica. Isto parece 
ser ansiosamente esperado pelos acadêmicos, que por vezes expressaram não estar preparados para esta nova etapa. Entretanto, observa-se que as expectativas desse período livre de disciplinas levam os estudantes a se preocupar não apenas com a relação estudante-paciente e o aprendizado a aprimorar, mas também com o acesso à residência médica.

\section{O Médico e a Profissão}

Antes de entrar na faculdade, a profissão e o médico exerciam um fascínio sobre esses jovens. Embora os aspectos referentes ao mercado de trabalho possam ter sido o atrativo principal para alguns, a imagem de um profissional humanizado e respeitado pode ter sido outra importante representação na escolha profissional. Observa-se que os acadêmicos chegaram ao curso bastante vocacionados, altruístas, desejosos de cuidar do outro. Nos depoimentos não se percebe preocupação com a saturação do mercado de trabalho, com escassez ou falta de lazer e mesmo com outras questões, como o erro médico.

"[...] Eu pensava que o médico era um profissional especial, quase um herói, que tinha a função de proteger a vida."

"[...] Que qualquer um tinha conhecimentos suficientes para enxergar o paciente além da sua especialidade."

"[...] Tinha pessoas muito próximas a mim que eram médicos e eu admirava muito o seu trabalho e a forma de fazê-lo."

No quarto ano, os acadêmicos já identificaram as dificuldades que o médico encontra no cotidiano. Alguns autores, como Arruda e Milan ${ }^{3}$, entendem que a percepção da necessidade de múltiplos empregos, a má remuneração, as péssimas condições de trabalho e até mesmo a redução do prestígio profissional tornam incompatível conciliar a ilusão construída com a realidade vivenciada:

\section{"[...] Para ganhar dinheiro é preciso trabalhar muito." \\ "[...] Ser médico é muito complexo, exige conhecimento, sen- sibilidade, estrutura emocional e confiabilidade."}

Mesmo neste contexto, sentem-se gratificados pela escolha e veem na medicina uma realização:

"[...] Acho que fazer medicina foi a melhor escolha que eu já fiz até o momento. Passei a ver que o retorno financeiro também faz parte, mas que ainda assim não deve ser o mais importante. É preciso fazer o que se gosta. Consegui superar muitos medos e hoje acredito que posso e serei uma ótima médica se continuar me superando, melhorando, buscando algo mais." "[...] Ainda acho que o médico é muito capaz de ajudar as pessoas e isso me agrada."
"[...] Acho que escolhi um caminho difícil para ajudar o próximo, mas não desistirei."

Essa motivação evidencia o processo de construção de uma identidade. Nesse momento, é possível que já reconheçam, entre médicos e professores, os modelos que representam seu ideal de profissional e, da mesma forma, aqueles que expressam a antítese desse ideal:

"[...] Quero ser mais humano, vejo absurdos por aí."

"[...] Vejo médicos insatisfeitos e até arrependidos com a escolha."

"[...] Enxergo a complexidade do sistema de saúde e a dificuldade de ser médico neste contexto."

Estes depoimentos sugerem a preocupação dos estudantes com as responsabilidades médico-sociais de suas práticas.

\section{Impressões sobre Si Mesmo}

É interessante observar como em alguns depoimentos os acadêmicos identificavam suas características pessoais na entrada na escola: pouco reflexivos, estudiosos, confusos, inseguros, ansiosos e preocupados com o despreparo para dar conta dos desafios do curso e da profissão. Isto parece natural na fase de vida em que se encontram - entre a adolescência e o início da vida adulta -, quando o confronto com as incertezas, contradições e ambivalência é uma constante. Para alguns autores, neste período o estudante de Medicina passa, provavelmente, por dois tipos de crise que se entrecruzam: aquela própria do adolescente tardio e a da escolha profissional que fez $z^{3,19}$.

"[...] Eu era uma pessoa muito aflita, com muitos medos: de não conseguir, de não ser forte, de passar mal."

"[...] Não me sentia capaz de estar neste curso."

"[...] Tinha uma visão simplista e objetiva da vida, só estudava, não pensava em nada."

"[...] Tenho dúvidas se tenho o dom para a profissão."

Ao mesmo tempo, observa-se em alguns depoimentos que os acadêmicos esperavam não apenas a aquisição de habilidades técnicas, mas um crescimento pessoal e de atitudes durante o processo de formação:

"[...] Insegurança perante of futuro; a universidade me aprimoraria como pessoa."

"[...] Pensava atingir realização pessoal e profissional."

Rogers e Rosemberg ${ }^{20}$ abordaram a necessidade de as pessoas se sentirem ouvidas para crescer; afirmavam que, quando uma pessoa é compreendida de maneira perceptiva, ela entra 
em contato mais próximo com uma variedade de vivências, o que lhe propicia ampliar o referencial a que recorrer para compreender a si mesma e nortear seu comportamento. Para eles, o processo de crescimento é especialmente permeado por relações empáticas. Nesse contexto, é necessário visualizar a escola e o docente como favorecedores do desenvolvimento de atitudes promotoras deste crescimento;

"[...] Hoje penso que tenho sim que me dedicar aos estudos, mas que também é importante ter momentos de descontração. Sou mais madura, segura, confiante, meu esforço pessoal valeu; estou aberta a novidades, abandonando os preconceitos gradativamente, sou muito mais flexível, aprendi a ver as coisas de uma outra maneira."

Sentem-se mais maduros, evidenciando que, nesse período, a família, definida por alguns como um porto seguro, o curso, a convivência com colegas e professores afetaram e produziram mudanças no seu próprio eu:

"[...] É preciso ter uma família para nos fortalecer e superar as dificuldades."

"[...] As amizades durante o curso me ajudaram a superar as frustrações."

O estabelecimento de relações empáticas com os colegas e professores aumenta a capacidade de autocompreensão e autoestima, sentimentos que podem estimular a criatividade, um aspecto importante a considerar no desempenho da prática médica.

Por outro lado, o grau de conflitos presente no curso de Medicina, em função do convívio com a dor, a morte e o sofrimento, uma realidade que frustra as expectativas trazidas com relação à escola, e mesmo as dificuldades específicas de cada um geram angústias, frequentemente causadoras de prejuízos ao bem-estar dos acadêmicos:

"[...] Qualidade de vida é zero; dedicação exclusiva ao curso; o mais difícil: dormir muito tarde e/ou acordar muito cedo, menor tempo de sono."

"[...] O curso gera muito sofrimento, dúvidas e perdas pessoais." "[...] Eu, que me achava de uma inteligência média, hoje me acho um "burro"; quanto mais passa o tempo, mais vejo que não sei nada. Penso que seria mais feliz fazendo um curso mais tranquilo. Penso que minha vida será sempre estressante e será difícil melhor qualidade de vida."

Também foi possível identificar depoimentos de desconforto e denúncias de dor que parecem não ter encontrado alívio:
"[...] Me sinto cada vez mais perdida e triste, parece que tudo o que eu sonhava desmoronou."

"[...] Sinto que estou caindo num abismo, acho que estou enlouquecendo e tenho medo disso! Só eu sei o que estou passando e ninguém vê."

Estes depoimentos remetem a um estudo realizado nesta universidade com 18 alunos de Medicina, ingressantes em 1996 e acompanhados ao longo do curso ${ }^{21}$. Os pesquisadores identificaram transtornos emocionais mais frequentes durante o terceiro e quarto anos, resultado semelhante ao de outros estudos $^{14-16}$. A oportunidade de identificar relatos de condição de sofrimento crônico a que se sentem submetidos alguns acadêmicos nesse estudo evidencia a necessidade de a escola estruturar e oferecer serviço de apoio durante a formação. Isto poderia favorecer o bem-estar do estudante, especialmente o mental, e contribuir para o processo de humanização do curso de Medicina.

\section{CONCLUSÃO}

Este estudo mostrou que no quarto ano de Medicina os acadêmicos derrotaram a idealização dos primeiros anos do curso. Apontou também que esses estudantes continuam comprometidos com a formação e esperam do internato um aprendizado conciliador. As relações interpessoais de confiança trouxeram influências positivas para o seu cotidiano.

Embora mais maduros e gratificados com a escolha, foi possível identificar acadêmicos em sofrimento que não encontraram estratégias para lidar com as adversidades surgidas ou acentuadas na graduação.

\section{REFERÊNCIAS}

1. Flick U. Uma introdução à pesquisa qualitativa. Porto Alegre: Bookman; 2004.

2. Bardin L. Análise de Conteúdo. Lisboa: Edições 70; 1977.

3. Arruda PCV, Millan LR. A vocação médica. In: Millan LR, DeMarco OLN, Rossi E, Arruda PCV. O Universo psicológico do futuro médico, vocação, vicissitudes e perspectivas. São Paulo: Casa do Psicólogo;1999. p.15-29.

4. Tollendal CB, Nogueira DG, Bartels FP, Paula FC, Braldo FMM. Fatores que orientam a escolha do curso médico. Rev Bras Educ Med. 2005;29(3):217-21.

5. Kaufman DM. Applical educational theory in practice. $\mathrm{Br}$ Med J. 2003;326:147-216.

6. Rawlins WK. Friendship matters. NY: Aldine de Gruyter; 1992.

7. Souza LK, Hutz CS. Relacionamentos pessoais e sociais: amizade em adultos. Psicol estud. 2008;13(2):257-65. 
8. Batista NA. O professor de medicina em sala: vivenciando uma prática. In: Batista NA, Silva SHB. O professor de medicina. São Paulo: Loyola; 1998. p 111- 124.

9. Abreu MC, Masetto MT. O Professor Universitário em aula: prática e princípios teóricos. S Paulo: MG Editores Associados; 1990.

10. Pimenta SG, Anastasiou LG. Docência no ensino superior. São Paulo: Cortez; 2002.

11. Brasil. Ministério da Saúde. Programa nacional de reorientação da formação profissional em saúde PRÓ-SAÚDE. Brasília:MS; 2005.

12. Costa NMSC. A formação e as práticas educativas de professores de medicina: uma abordagem etnográfica. São Paulo; 2005. Doutorado [Tese] — Pontifícia Universidade Católica de São Paulo.

13. Millan LR. O curso médico no Brasil. In: Millan LR, De Marco OLN, Rossi E, Arruda PCV, org. O Universo psicológico do futuro médico, vocação, vicissitudes e perspectivas. São Paulo: Casa do Psicólogo; 1999. p.31-42.

14. Mosley Junior TH, Perri SG, Neral SM, Dubbert PM, Grothues CG, Pinto BM. Stress, Coping, and Well-being among Third-year Medical Students (short papers). Acad Med.1994;69(9):765-67.

15. Firth J. Levels and sources of stress in medical students. Br Med J. 1986;292:1177-80.

16. Guthrie EA, Black D, Shaw CM, Hamilton F, Creed FH, Tomenson B. Embarking upon a medical career: psychological morbidity in first year medical students. Med Educ. 1995;29:337-41.

17. Millan LR, Rossi E, DeMarco OLN. A psicopatologia do estudante de medicina. In: Millan LR, De Marco OLN, Rossi E, Arruda PCV, org. O Universo psicológico do futuro médico, vocação, vicissitudes e perspectivas. São Paulo: Casa do Psicólogo;1999. p.83-94.

18. Arruda PCV. As relações entre alunos, professores e pacientes. IN: Millan LR, De Marco OLN, Rossi E, Arruda PCV. O universo psicológico do futuro médico: vocação, vicissitudes e perspectivas. São Paulo: Casa do Psicólogo; 1999. p.43-73.

19. Millan LR, De Marco OLN, Rossi E, Millan MPB, Arruda $\mathrm{PCV}$. Alguns aspectos psicológicos ligados à formação médica. In: Millan LR, De Marco OLN, Rossi E, Arruda PCV, org. O Universo psicológico do futuro médico, vocação, vicissitudes e perspectivas. São Paulo: Casa do Psicólogo; 1999. p.75-82.

20. Rogers CR, Rosemberg RL. A pessoa como centro. São Paulo:EPU;1977. 228 p.

21. Benevides-Pereira AMT,Gonçalves MB. Transtornos Emocionais e a Formação em Medicina: um estudo longitudinal. Rev Bras Educ Med. 2009;33(1):10-23.

\section{CONTRIBUIÇÃO DOS AUTORES}

Rosangela Ziggiotti de Oliveira idealizou o projeto e participou da revisão da literatura, assim como da aplicação dos instrumentos e análise dos resultados. Contribuiu na interpretação dos resultados e participou na elaboração e da redação final deste artigo. Maria Bernadete Gonçalves participou no processo de elaboração e discussão do projeto, revisão da literatura, digitação dos relatos e análise dos resultados. Participou também na elaboração e correção do relatório final do projeto e redação deste artigo. Luzia Marta Bellini participou ativamente na seleção da bibliografia pertinente, na classificação dos relatos dos estudantes e o arranjo por categorias, assim como na análise do conteúdo e interpretação dos resultados.

\section{CONFLITO DE INTERESSES}

Declarou não haver.

\section{ENDEREÇO PARA CORRESPONDÊNCIA}

Rosangela Ziggiotti de Oliveira

Av. Mandacarú, 1590 - Bloco S - sala 10 Zona 7

Parque das Laranjeiras - Maringá

CEP.87083-240 PR

E-mail: rzo13@hotmail.com 